\title{
In Defense of a Category-Based System for Unification Admissions
}

\author{
Matthew Lindauer \\ Brooklyn College, CUNY \\ Australian National University \\ Forthcoming in the Journal of Moral Philosophy
}

This paper is concerned with the contributions that being in different types of

relationships with a member of a society should make to an immigrant's prospects of getting into and acquiring membership in that society. My goal in the paper is to provide considerations of political morality, which often diverge in various ways from moral ideals that do not have to be implemented within the constraints of actual political societies. I will focus on feasibility constraints that are generated by non-ideal features of our world, such as the fact that most societies have limited resources that constrain the overall number of immigrants that they can admit in a given period of time. The morally appropriate treatment of different "unification admissions," non-members seeking admission for the purpose of living in the same society with members on a stable basis, is the focus of the paper. I argue that a principled distinction can be drawn between unification admissions that societies should treat as legally obligatory to allow in and those that societies should treat as legally optional.

Proponents of the traditional state sovereignty view on immigration, who argue that societies have wide latitude in setting their immigration policies, have tended to treat family

\footnotetext{
${ }^{1}$ This term is borrowed from the more typical term "family reunification," which is misleading. Unification is more apt as a description of the kinds of policies that are discussed under the umbrella of family reunification policies because some family members have never lived in the same society, or even met one another, and are covered by these policies. They may still have important claims to be able to "unify" in the political sense, living in the same society on the stable basis that co-membership affords.
} 
reunification as an exception. For instance, Michael Walzer holds that the powers to control admission and exclude prospective newcomers "suggest the deepest meaning of selfdetermination." ${ }^{2}$ States can only function as self-determining political communities if they can take in and refuse immigrants largely as they see fit, and so they must have the right to do so. Nevertheless, Walzer holds that it is "especially appropriate" ${ }^{3}$ for states formed largely by the admission of immigrants, such as the United States, to recognize what he calls the "kinship principle," which commits them to giving "priority in immigration to the relatives of citizens." Christopher Heath Wellman also argues for the right of states to exclude. ${ }^{4}$ For him, this right follows from a state's freedom of association. Yet because this freedom is ultimately grounded in the freedom of association of members of the state, and some members will have important interests in associating with family members that can only be fulfilled by bringing these persons into the state, Wellman holds that family reunification may be an exception to the state's right to exclude. $^{5}$

Against these theorists, Luara Ferracioli has recently argued that, insofar as societies are morally required to prefer family members and spouses of their members seeking to immigrate, they must also give the same status to other persons who members bear equally important ties to, including friends and creative partners. ${ }^{6}$ My approach in this paper diverges from both the traditional state sovereignty view and Ferracioli's approach. I do not hold that societies have

\footnotetext{
${ }^{2}$ Michael Walzer, Spheres of Justice: A Defense of Pluralism and Equality (New York: Basic, 1983), p. 62.

${ }^{3}$ Ibid., p. 41.

${ }^{4}$ Christopher Heath Wellman, 'Immigration and Freedom of Association', Ethics, Vol. 119, No. 1 (October 2008), pp. 109-141; Phillip Cole and Christopher Heath Wellman, Debating the Ethics of Immigration: Is There a Right to Exclude? (New York: Oxford University Press, 2011). ${ }^{5}$ Cole and Wellman, Debating the Ethics of Immigration, p. 92.

${ }^{6}$ Luara Ferracioli, 'Family Migration Schemes and Liberal Neutrality: A Dilemma', Journal of Moral Philosophy, Vol. 13, No. 5 (2016), pp. 553-575.
} 
wide latitude to exclude non-members as they see fit. However, I disagree with Ferracioli's contention that societies are not morally permitted to treat family members and spouses differently from other persons with whom members stand in important relationships. I will argue that there are good reasons to distinguish between family members that societies should take on an obligation through their immigration laws and procedures to let in and other unification admissions. While I agree with Ferracioli's point that on a case-by-case basis there will often be friendships and other relationships that match parent-child and marital relationships in importance for particular people, this doesn't yet show that societies must allow for the unification of these relationships within their borders. Nor does the fact that some people are in closer relationships with their grandparents than their parents imply that grandparents and parents should be treated on a par by actual immigration policy regimes. ${ }^{7}$ My view supports a three-way distinction between non-members in relationships with members who should be treated as legally obligatory to let in, those who should be treated as legally optional to let in but preferred over general admissions, and those who need not be given any unification admissions status.

\section{Obligatory and Optional Unification Admissions}

It is more important that some people be allowed to unify in a society than others. For instance, it seems clear that two spouses in a genuine, mature romantic relationship have a stronger claim to be able to bring one of them into a society than two other spouses who are

\footnotetext{
${ }^{7}$ If grandparents played the "parental role" in a person's life whereas their biological parents did not, my view recommends the opposite conclusion. I clarify what is meant by the parent role and how such factors can be accommodated by an immigration policy regime in Section 4.
} 
legally still married but no longer romantically involved, all else being equal. This is all obvious so far, but recognizing the variation among potential unification admissions requests raises interesting questions for theorists who want to understand what are the morally appropriate statuses for societies to give these different requests.

Immigration policy regimes must include policies for handling unification admissions, which in most countries constitute the largest group of newcomers. ${ }^{8}$ Immigration officials, however, only ever have imperfect information about the veracity and importance of different unification requests, an epistemic situation that cannot be overcome entirely by requesting more documents, running genetic tests, or conducting more interviews. How then can theorists working in the ethics of immigration draw distinctions between different unification admissions requests and understand whether immigration policies of existing societies that distinguish between such requests are morally defensible?

The non-members who are given some preferential treatment by a society's immigration policy regime on the basis that they are in some type of relationship with an existing member of the society are, for my purposes, the persons that society recognizes as unification admissions. My view is that a principled distinction can be drawn between two recognized categories of unification admissions, and also a third category of unification admissions that a society does not recognize in any official way. "Obligatory unification admissions," as I will refer to them, are unification admissions that the society takes on a legal obligation to allow in. By contrast, "optional unification admissions" are given some extra consideration as compared to the general pool of immigrants but the society does not take on a legal obligation to admit them. The terms

\footnotetext{
${ }^{8}$ Stephen Castles, Hein de Haas, and Mark J. Miller, The Age of Migration: International Population Movements in the Modern World, 5th edn (Hampshire: Palgrave Macmillan, 2014), p. 7; OECD, 'A Portrait of Family Migration in OECD Countries', in International Migration Outlook 2017 (Paris: OECD Publishing, 2017).
} 
"obligatory" and "optional" as I use them in this paper are shorthand for "legally obligatory" and "legally optional" unless otherwise specified. The position that I will spend most of the paper arguing for is that certain unification admissions should be placed into the legal category of the persons whom a society is required to take in under its immigration laws, the obligatory unification admissions. Granting this legal status to certain unification admissions does not make it the case that they cannot be refused under any circumstances. If a non-member is a terrorist or is found to be carrying a contagious disease the transmission of which could create a public health emergency, to give some examples, they may still be refused despite having this status. Obligatory unification admissions are persons who must be allowed in unless some very pressing reasons can be given for keeping them out. Other reasons for excluding them, such as that there are too many other immigrants seeking to get in through another category, are taken off the table. By contrast, optional unification admissions here are persons whom a society has the option to exclude even without very pressing reasons. Optional admissions may be excluded because there are too many immigrants from another category seeking to enter that the society wishes to bring in, for instance. As I said, there may also be other unification admissions, nonmembers seeking to unify with a member of a society whom the society need not treat differently from general admissions. I will focus predominantly on the first category in this paper and which unification admissions should be placed in it, but I will also say a bit about the second and third categories and how they might be separated from one another.

As Ferracioli emphasizes with numerous examples, actual relationships vary across types in their importance for particular persons. ${ }^{9}$ A friendship may be especially important to someone given their rich history with a friend and the ways in which they've supported one another over

\footnotetext{
${ }^{9}$ Ferracioli, 'Family Migration Schemes and Liberal Neutrality: A Dilemma.'
} 
time. A creative partnership may also be of special value in a person's life that is not obviously of lesser value than their relationships with other persons. We cannot reliably draw any conclusions about the strength of the bond between two people from the fact that they are in a parent-child, marital, sibling, or another type of relationship with one another. This is plausibly true, although it leaves open the question of whether the ideal forms or best instances of each type of relationship might differ in their moral significance. Even if this were the case, however, there is a further constraint that liberal democracies recognize, which Ferracioli refers to as the constraint of "liberal neutrality." 10 This is the requirement that liberal societies refrain from implementing laws and institutional arrangements that are justified by reference to conceptions of the good that are subject to reasonable disagreement. I will return to the constraint of liberal neutrality after presenting my view and show that it does not violate this constraint.

\section{Obligatory Unification Admissions}

What could make it the case that certain persons that members of a society are in important relationships with should be treated as obligatory unification admissions? It has become standard in the ethics of immigration literature to consider the weightiness of interests that either support or fail to support unification schemes. ${ }^{11}$ It will also be useful in putting

\footnotetext{
${ }^{10}$ Ibid., p. 554.

${ }^{11}$ Ferracioli distinguishes between strong and weak interests in this context (Ibid., pp. 563-564). Joseph Carens uses the term "vital interests" in his discussion of family reunification (see Joseph Carens, The Ethics of Immigration (Oxford: Oxford University Press, 2013), pp. 185-191). Matthew Lister refers to "important interests" in reunification in his discussion of the requirement to give equal access to family reunification to heterosexual and homosexual married couples (see Matthew Lister, 'A Rawlsian Argument for Extending Family-Based Immigration Benefits to Same-Sex Couples', The University of Memphis Law Review, Vol. 37 (Summer 2007), pp. 745-780).
} 
forward my view of the justification for these schemes and the shape that they should take to distinguish between fundamental interests and non-fundamental interests. Fundamental interests, as I will understand them, are interests whose fulfilment is important to an agent's having a meaningful and worthwhile life. Non-fundamental interests, by contrast, are interests the fulfilment of which is not important in this way. I hold that one of the fundamental interests of persons is the interest in participating in and maintaining certain close relationships with other persons. This claim does not entail that the fulfilment of this interest is either sufficient or necessary for having a meaningful and worthwhile life. In terms of sufficiency, surely other interests must be fulfilled for one to have such a life, including many very mundane subsistencebased interests in being nourished, having shelter, and so on. Perhaps some of these should be singled out as "basic interests," because their fulfilment is required for physical survival, but this doesn't require us to deny that other interests are fundamental in the intended sense. Which other interests must be fulfilled to give one a meaningful and worthwhile life is an interesting philosophical question that I cannot address here. ${ }^{12}$ In terms of necessity, it may be that a life could be meaningful and worthwhile, in at least some cases, even in the absence of these particularly close relationships with other persons if enough other important interests are fulfilled. One would expect that the life of a reclusive monk could be very meaningful and worthwhile, even if not the kind of life that the vast majority of people would choose for themselves. But in typical cases people require certain close relationships with other persons to sustain a meaningful and worthwhile existence.

\footnotetext{
${ }^{12}$ For an important recent attempt to address the question of what is involved in living a meaningful life, see Susan Wolf, Meaning in Life and Why It Matters (Princeton: Princeton University Press, 2012).
} 
Two points are then worth noting, one of which I have just discussed. The first is that certain relationships with other persons are typically important parts of a meaningful and worthwhile life. Normally, we think of certain family and romantic relationships as constituting an important class of such relationships. People have fundamental interests in participating in and maintaining these relationships with others. The second is that these relationships can be composed of members and non-members of given societies. Indeed, given the freedom of movement and exit afforded to members of modern democratic societies, their members may be more likely, in general, than members of other societies that limit movement and exit more systematically to participate in these relationships with non-members. I will sometimes refer to relationships that members of a society stand in with non-members of that society as "external relationships."13

A third point is that sometimes these fundamental interest of persons can only be fulfilled by a society allowing some non-members to immigrate. For instance, a member of society may have an elderly parent that they can only participate in and maintain their relationship with by bringing them into their society on the stable basis that membership makes possible. They might not be able to join their parent's society if that society has very strict immigration rules. Alternatively, if the member is gay and gay people face violent discrimination in the society where their parent lives, they may not be able to move there without taking on very serious risks. To take another example, a parent who is a member of society that has been separated from their children who do not currently have membership may need to bring their children into the society on the stable basis that membership affords them. Otherwise, this member may not be able to continue to provide a secure developmental environment and care for them in the ways required

\footnotetext{
${ }^{13}$ Matthew Lindauer, 'Immigration Policy and Identification Across Borders', Journal of Ethics and Social Philosophy, Vol. 12, No. 3 (2017), pp. 280-303.
} 
by their parental duties. Spouses who have been separated from one another may also need to unify in the society where one spouse is a member in order to continue to participate in and maintain their relationship with one another. Relationships may require unification in a society when the parties to them cannot unify, or cannot do so without taking on unreasonable risks and costs, in another society.

\section{Obligatory Unification Admissions and Feasibility Constraints}

I noted earlier that a case-by-case assessment shows that there are many types of relationships that can be very important to us and there is no necessary connection between a given relationship's type and how important it is to the people in it. Unfortunately, however, societies face a number of practical hurdles to treating all persons in important relationships with their members as obligatory unification admissions. According to Ferracioli's view, the differential treatment given to these relationships violates the requirement of liberal neutrality. But this conclusion, I will argue, ignores a set of important feasibility constraints that societies face when implementing unification admissions policies. ${ }^{14}$

From the perspective of desirability, it is natural to think that states ought to treat all external relationships that are equally important to the people in them equally. ${ }^{15}$ It would be a good thing to do this if and when it is practically possible and there is a moral cost to not doing so; people who stand in important relationships with one another are not granted the same

\footnotetext{
${ }^{14}$ I am grateful to Nic Southwood for helpful discussion on the role that feasibility considerations play in my argument.

${ }^{15}$ On the contrast between desirability and feasibility, see Robert E. Goodin and Philip Pettit, 'Introduction', in A Companion to Contemporary Political Philosophy, eds. Robert E. Goodin and Philip Pettit (Oxford: Blackwell, 1995).
} 
treatment as other people in relationships that are equally important for them. However, it is widely held that considerations of feasibility, in addition to desirability, should inform the policy proposals that we put forward as political philosophers. The concept of feasibility is becoming an important topic in its own right in political philosophy, particularly in discussions surrounding the ideal/non-ideal theory debate. ${ }^{16}$ Feasibility considerations, I hold, are an important part of the explanation of why states are justified in using category-based systems for unification admissions and not judging external relationships on a case-by-case basis.

Of course, there are many different kinds of considerations that involve feasibility, and not all of these should count against a particular view on immigration policy. ${ }^{17}$ For instance, the fact that states and their citizens aren't motivated to adopt a given policy is not a reason in favor of a competing policy, even though this fact increases the likelihood that the second policy will be adopted rather than the first. ${ }^{18}$ This is not the kind of consideration that I will appeal to in arguing for a category-based scheme over a case-by-case scheme of the kind envisioned by Ferracioli. Nor do I think that any of the "hard constraints of" logical, conceptual, metaphysical,

\footnotetext{
${ }^{16}$ Goodin and Pettit, 'Introduction'; Juha Räikkä, 'The Feasibility Condition in Political Theory', Journal of Political Philosophy, Vol. 6, No. 1 (1998), pp. 27-40; Geoffrey Brennan and Philip Pettit, 'The Feasibility Issue', in The Oxford Handbook of Contemporary Philosophy, eds. Frank Jackson and Michael Smith (Oxford: Oxford University Press, 2005), pp. 258-279; Pablo Gilabert, 'Feasibility and Socialism', Journal of Political Philosophy, Vol. 19, No. 1 (2011), pp. 52-63; Pablo Gilabert and Holly Lawford-Smith, 'Political Feasibility: A Conceptual Exploration', Political Studies, Vol. 60, No. 4 (2012), pp. 809-825; Holly Lawford-Smith, 'Understanding Political Feasibility', Journal of Political Philosophy, Vol. 21, No. 3 (2013), pp. 243-259; David Miller, Justice for Earthlings: Essays in Political Philosophy (Cambridge: Cambridge University Press, 2013); David Wiens, 'Political Ideals and the Feasibility Frontier', Economics and Philosophy, Vol. 31, No. 3 (2015), pp. 447-477.

${ }^{17}$ I am grateful to an anonymous reviewer for urging me to clarify which types of feasibility considerations are and are not relevant in this context.

${ }^{18}$ Lawford-Smith, 'Understanding Political Feasibility', p. 256.
} 
or nomological impossibility rule out such an approach. ${ }^{19}$ As opposed to hard feasibility constraints, which make it the case that an outcome cannot obtain, "soft feasibility constraints" are facts that make an outcome less likely to obtain. It is soft constraints that are typically discussed in political philosophy and that are thought to be relevant to the assessment of policies and political principles. Unlike hard constraints, soft constraints are not absolute, and so it is compatible with changing conditions that their import on a given political issue may change. There is reason to think, however, that a set of important soft constraints render a case-by-case system infeasible for the foreseeable future, and this fact helps to explain why a category-based system need not violate the principle of liberal neutrality.

First, even very large societies that are low in population density may not be able to take in all the persons who want to come in a given year. If they are meeting their domestic justice responsibilities, they must use public resources to support their members in various ways, such as through the provision of public healthcare and unemployment benefits. They must also extend equal protection of the law to all members, which involves distributing resources to courts, police, and public defenders, among other legal entities. ${ }^{20}$ Given these resource

${ }^{19}$ On the contrast between hard and soft constraints of feasibility, see Gilabert and LawfordSmith, 'Political Feasibility: A Conceptual Exploration', and Lawford-Smith, 'Understanding Political Feasibility'.

${ }^{20}$ Michael Blake, 'Immigration, Jurisdiction, and Exclusion', Philosophy and Public Affairs, Vol. 41, No. 2 (2013), pp. 103-130. Notably, immigration courts often face much greater burdens than others. As of April 2017, the backlog of immigration cases in the United States waiting for a decision reached an all-time high of 585,930 cases, with individuals waiting an average of 670 days for their case to be heard, according to Syracuse University's TRAC Immigration Project (see http://trac.syr.edu/immigration/ reports/468/, accessed September 20, 2017). A 2010 American Bar Association report found that immigration judges in the U.S. receive an average of roughly 1,250 new cases per year, approximately 550 more cases than federal judges hearing social security or veteran law cases. See American Bar Association Commission on Immigration, Reforming the Immigration System: Proposals to Promote Independence, Fairness, Efficiency, and Professionalism in the Adjudication of Removal Cases, 2010, 
constraints and the numerical limits on how many people can be taken in that they give rise to, there is potential competition among different types of admissions. This is not to say that all countries will necessarily have to impose limits on immigration. When these constraints are not applicable, as I have noted above, it would be best to allow all persons in morally significant relationships with members in. But there is substantial evidence that societies typically do face these constraints. ${ }^{21}$ As a result, they must adopt priorities for the different streams of migrants that they will take in, and increasing allowances for one stream, such as unification admissions, can reduce the number of migrants that can be taken in through another stream. ${ }^{22}$

Most societies do not experience only one type of migration pressure, but are subject instead to what is often referred to as "differentiation of migration" - a range of different types of admissions including family members, skilled workers, and asylum seekers. ${ }^{23}$ Notably, family reunion, in particular the entry of dependent children, spouses, and other relatives of previous primary migrants, remains the largest entry category in many countries. ${ }^{24}$ Societies that already face great demands to bring in family members often have responsibilities to bring in other persons. In many cases, they have asylum seekers arriving and claiming refugee status that they have moral and international legal obligations to use resources to take in and determine the status

www.americanbar.org/content/dam/aba/publications/commission_on_immigration/coi_ complete_full_report.pdf, accessed September 20, 2017.

${ }^{21}$ See Anna Boucher, Gender, Migration, and the Global Race for Talent (Manchester: Manchester University Press, 2016); OECD, 'Trends in International Migration', SOPEMI 2006 Annual Report (Paris: OECD Publishing, 2006); OECD, 'A Portrait of Family Migration in OECD Countries'; and Elaine Chao and Arnold Levine, 'Integrating Immigrants Into the Workforce: North American and European Experiences', Bureau of International Labor Affairs U.S.-E.U. Papers, July 28-29, 2004.

${ }^{22}$ Boucher, Gender, Migration, and the Global Race for Talent, p. 69; OECD, 'Trends in International Migration', pp. 112-125.

${ }^{23}$ Castles, de Haas, and Miller, The Age of Migration: International Population Movements in the Modern World, p. 16.

${ }^{24}$ Castles, de Haas, and Miller, The Age of Migration: International Population Movements in the Modern World, p. 7; OECD, 'A Portrait of Family Migration in OECD Countries'. 
of. Further, to avoid being disadvantaged in the global economy they must often leave room for some skilled workers and their families to come and join their leading universities, corporations, and other "centers of excellence." ${ }^{25}$ If societies that set annual limits on immigration were morally obligated to allow in every cousin or friend of every one of their members, less room would be available for other inflows. ${ }^{26}$ It would be more difficult for them to fulfill their other immigration-related responsibilities, such as taking in asylum seekers requesting refugee status, and bring in skilled workers, which in many cases benefits the sending and receiving societies, ${ }^{27}$ if unification admissions significantly increased.

To put the point slightly differently, a state's immigration policy regime should be set up not only so as to maximally satisfy people's fundamental interests in unifying with others. It must also answer to the state's other immigration-related responsibilities, such as the duty to take in refugees. In doing so, a feasible immigration policy regime will avoid "making the best the enemy of the good." I acknowledge that the best possible immigration policy regime would take in all refugees seeking asylum, allow all persons to immigrate who stand in morally significant relationships with citizens, and still allow for labor migration to support important collaborative

${ }^{25}$ I am grateful to Steve Darwall for pointing out the relationship between centers of excellence and skilled migration.

${ }^{26}$ See Boucher, Gender, Migration, and the Global Race for Talent, pp. 69-93, for an important discussion of the ways in which family migration and asylum seekers compete with other admissions. Boucher also discusses the similar measures that were taken in Australia and Canada in the late twentieth century to restrict family admissions in order to increase skilled worker admissions. For the competition between skilled and family migration in the United States, see Gerry Mackie, 'U.S. Immigration Policy and Local Justice', in Local Justice in America, ed. Jon Elster (New York: Russell Sage Foundation, 1995), pp. 227-290. See also OECD, 'Trends in International Migration', pp. 112-125.

${ }^{27}$ See Gillian Brock, Global Justice: A Cosmopolitan Account (Oxford: Oxford University Press, 2009), Christian Barry, 'Immigration and Global Justice', Global Justice: Theory, Practice, and Rhetoric, Vol. 4, No. 1 (2011), pp. 30-38, and Gillian Brock and Michael Blake, Debating Brain Drain: May Governments Restrict Emigration? (Oxford: Oxford University Press, 2015) for competing moral assessments of developed societies accepting skilled workers from developing societies. 
research and corporate ventures. But doing all of these things, the empirical evidence suggests, would be infeasible for most existing societies, and so a balance must be struck that properly responds to the human interests and claims involved. Here I am holding fixed a few commitments that Ferracioli and I share, in particular the duties of states to take in refugees and, presumably, the permission of states to bring in at least some skilled workers. With these fixed points, I am then considering the shape that a unification admissions policy should take, subject to the first resource-based feasibility constraint just discussed.

Second, as Ferracioli acknowledges at one point, a state must often make use of clear-cut, objective criteria in implementing its immigration policies. ${ }^{28}$ Using clear-cut, publicly-known criteria has important benefits over a system that relies too heavily on the discretion of officials. It reduces the amount of resources that go into immigration administration and lag in the system, both problems that existing societies often struggle with. ${ }^{29}$ Clear guidelines for unification admissions will also do a better job of realizing the aim of unification policies, fulfilling the interests of persons in unifying, because citizens and non-citizens who stand in important relationships with one another can anticipate the results of their unification requests in advance to a greater extent. These are fundamental or strong interests of theirs, and being able to apply for unification with clear guidelines about how to go about doing so and what to expect is therefore especially useful to them. Further, drawing on the importance of the interests involved in unification, clear-cut, general, and public guidelines rely less heavily on the discretion of immigration officials in determining whether or not people are allowed to live in the same state. With weighty interests of this kind, it is more important to avoid false negatives, preventing

\footnotetext{
${ }^{28}$ Ferracioli, 'Family Migration Schemes and Liberal Neutrality: A Dilemma', p. 574, note 34. ${ }^{29}$ Castles, de Haas, and Miller, The Age of Migration: International Population Movements in the Modern World.
} 
people who are genuinely in these important relationships from unifying, than false positives, allowing some people who aren't genuinely in these relationships to do so. While some discretion will have to be involved in assessing whether or not claims are fraudulent, as in the case of interviews for people who are seeking to unify as spouses, it is best to give clear guidelines that limit the discretion of individual immigration officials when such important interests are at play. So a category-based system will also be more feasible than a case-by-case system in virtue of providing clear-cut, objective criteria that rely less on the discretion of officials assessing unification admissions requests.

Third, states must avoid implementing unification policies that make it difficult to detect fraudulent claims. Because people admitted through unification policies, as noted earlier, use societal resources and compete with other prospective newcomers for limited offers of admission, it is important that their claims be genuine and that the state have means to reliably assess the authenticity of their ties to an insider. Of course, reliability does not imply infallibility in assessing these claims, which is an impossibly high standard that would prevent all external relationships from being recognized for immigration purposes. But the use of categories that pick out external relationships that are reasonably verifiable and more difficult to fake will be more feasible for an immigration policy regime than assessing relationships on a case-by-case basis. I will say more about verifiability and the ability to detect fraudulent relationships in the following sections, where I compare potential categories of unification admissions. The point to make at this stage is that categories allow immigration policy regimes to set unification admissions policies that focus on relationships that generally can be verified and that are difficult to fake, making it more feasible for a society to bring in unification admissions while still meeting its other immigration-related responsibilities. 
There is a tension, then, between the case-by-case approach and acknowledging the feasibility constraints that actual societies are generally subject to when administering their immigration policies. This tension provides a prima facie justification for seeing whether the practice that societies typically engage in of distinguishing between different relationships in their immigration policies could be justified. We approach this question fully aware that there are moral costs in not being able to take on a legal obligation to bring in every person that is in a morally significant relationship with a member of society. The persons whom we treat as legally obligatory unification admissions, on this approach, are a subset of those whom we would be morally obligated to let in if we didn't face the feasibility constraints just discussed. A society is morally obligated to implement an immigration policy regime that takes these factors into account and uses clear-cut, practically feasible rules that give appropriate consideration to the fundamental interests of, at least, all its members. ${ }^{30}$ This does not, however, imply that all members can have their fundamental interests in bringing people in fulfilled by these arrangements.

Which non-members, then, should be treated as obligatory unification admissions? I argue that, roughly, they are parents, children, and spouses of members. I will start by discussing parents and children, by which I meant to include parents and non-adult unmarried children of members, and then move on to discuss spouses.

\footnotetext{
${ }^{30}$ I will say more about the interests of members and non-members below, and how a clearer understanding of the interests at stake in implementing different kinds of unification schemes is important for the justification of categories of unification admissions.
} 


\section{Parents and Non-Adult Unmarried Children}

Although not all people have especially close relationships with their parents, in typical cases parents are among the other people whom we value most and bear the closest ties to in our lives. In usual circumstances, parents raise their biological children and play the crucial role in securing the conditions under which they grow and become adults. Parents provide for our moral education and encourage us to develop our own moral agency. ${ }^{31}$ The love of parents, which is often thought of as unconditional, can help to create a stable disposition towards selfrespect in a child. Parents help us to make decisions about our futures and become the persons we want to be. It is not at all surprising that people whose parents fulfill these functions, which are often thought of as parental duties, ${ }^{32}$ come to value their relationships with their parents as some of the most important ones in their lives. Parents typically fulfill these unique roles in their children's lives, and children's ties to their parents are made especially strong in a lasting way as a result. ${ }^{33}$ A parent often provides a supportive anchor in life than is not equaled in other relationships. I emphasize these considerations to highlight some of the features that make parent-child relationships strong, distinctive, and irreplaceable. ${ }^{34}$ No other relationship involves

31 J. David Velleman, 'Beyond Price', Ethics, Vol. 118, No. 2 (January 2008), pp. 191-212.

${ }^{32}$ Perhaps some of these are more demanding than what is morally required, but engaging in this debate would go beyond the bounds of this paper.

${ }^{33}$ Notably, each of these roles just mentioned can be fulfilled by adoptive parents, stepparents, or other members of the family whom societies make eligible to adopt or attain legal custody over the child. In these cases, a child may become far closer to other persons who play the parental role in their lives just described, involving nurturing and helping them to develop into an adult, than their biological parents. My use of the term 'parent' is intended to capture all of these persons.

${ }^{34}$ My strategy here is to appeal to commonly accepted features of different human relationships to show that we may draw a principled distinction between different unification admissions. While I offer one line of reasoning in support of the claim that members have standing to demand that their society allow them to bring in certain non-members, this claim is not in dispute 
the same expectations of nearly unconditional love and support that parents are supposed to have for their children.

Given these features, it is often the case that people see themselves as having important responsibilities to their parents as adults. Aging parents often require care and emotional support through the later stages of life. While other persons may be able to provide this care, their adult children often will want to do so insofar as they are able, reciprocating the support that they received from their parents during their childhoods. Additionally, adult children will want to be able to spend time with the parent as they approach the end of their life. If someone has moved to another country for career or other personal reasons, it may be very hard for them to continue their new located life-plans, involving personal and professional responsibilities that must be fulfilled there, ${ }^{35}$ while remaining without their parent.

These points support the view that people typically have a fundamental interest in participating in and maintaining close relationships with their parents. In circumstances where a member of society cannot without great cost immigrate to another society where their parent lives, this interest will be frustrated if their parent cannot immigrate to their own society. And in many cases, it will be urgent that parents be allowed in at later stages in their lives, when they have limited time remaining to spend and be cared for by their families. If the parent lives in a society where their adult children could not live safely, for instance a society where gay people are at risk of violent attacks when their child is gay, the response that the child could just move to their parent's society simply won't do. As a member of society, their children may also have

between Ferracioli and I. I am grateful to an anonymous reviewer for pushing me to clarify the relation of this claim to my overall argument.

${ }^{35}$ I borrow the term "located life-plan" from Anna Stilz. See Anna Stilz, 'Occupancy Rights and the Wrongs of Removal', Philosophy and Public Affairs, Vol. 41, No. 4 (2013), pp. 324-356.

Stilz intends for the term to capture situated goals, relationships, and projects. 
found important projects that support their livelihood or started a family of their own that they cannot leave.

People usually have a maximum of two legal parents in modern democratic societies, and it is fairly easy to verify in most cases, through either DNA tests or legal documents, that someone is your parent. So there is little risk of overburdening immigration quotas or overtaxing societal resources by allowing members to bring in their parents. Giving obligatory unification admissions status to parents is perfectly compatible with having a feasible immigration policy regime that meets its other immigration-related responsibilities.

Summing up, parents are some of the people that we are often the closest to in our lives. But additionally, it is often important to be able to bring a parent into one's society, especially at certain stages of their lives, to continue to participate in and maintain one's relationship with them. Further, because people usually have only two parents and parental relationships are relatively easy to verify, allowing members of society to bring in their parents does not bump up against the feasibility constraints discussed in Section $3 .^{36}$ These are three plausible considerations that speak in favor of giving obligatory unification admissions status to parents as part of a feasible immigration policy regime.

\footnotetext{
${ }^{36}$ It is worth noting that existing unification schemes typically only grant obligatory unification status to the parents of adult members of society. I will flag the point here that there may be good reasons to limit obligatory unification admissions status to parents of adult members of society in societies that use jus soli or "birthright citizenship" in order to avoid creating perverse incentives to have children in these societies to gain citizenship for oneself. Although this problem does not exist in the U.S. currently, despite the public rhetoric surrounding "anchor babies" from some quarters, it is one that a society may legitimately avoid creating. However, this does not imply that it is morally permissible to keep these parents out entirely, to treat them as general admissions, or to deport them if they are present in the country illegally and have committed no serious crimes. A fuller discussion of this interesting and practically important issue would go beyond the purview of this paper. The considerations above should be taken to apply to at least parents of adult members of society.
} 
The next group of admissions that should be placed in the obligatory unification admissions category are children, specifically non-adult unmarried children, of members of society. ${ }^{37}$ Some of the points that I will make here also add to the support for the claim that parents should be treated as obligatory unification admissions. My view is that the interests of members in bringing in their parents are strong enough to generate an obligation on the state to admit parents, given the absence of feasibility considerations that militate against doing so. But the fact that non-member parents often have strong interests in being in the same societies as their children provides further support for the claim that they should be allowed to immigrate to the societies where their children live. However, societies are only obligated to allow people to bring in their children, I hold, when these children have not reached adulthood or started a family of their own by getting married. I will say why this restriction should be used shortly, but will first discuss the reasons why I hold that non-adult unmarried children should be allowed in.

I mentioned earlier that children often seek to reciprocate the care that their parents provided for them early in life as a reason for allowing parents to immigrate and live in the same society as their adult children. Implicit in this point is the prior fact that parents typically care for their children in distinctive and important ways. People who put in the effort of parenting children typically take on costs to themselves in doing so by restricting the financial and other resources they have to pursue other interests. They typically become invested in the child's future and seek to help them to develop into full adults. There are interests that people who take on the parenting role develop in caring for and supporting their children. Additionally, there

\footnotetext{
${ }^{37}$ As in the case of parents, my discussions of the considerations that favor placing non-adult unmarried children of members in the obligatory unification admissions category is intended to include adopted children and stepchildren.
} 
may be general interests in parenting that all human beings possess,${ }^{38}$ but this view is controversial and difficult to reconcile with the fact that many people live what seem to be very meaningful and worthwhile lives without having or raising children. What is uncontroversial is that people who already have or are raising children often have important interests in maintaining close relationships with them.

If all of this is right, why would parents ever wind up having to bring in their children from abroad, rather than merely staying in the same society as them? There are a number of ways in which this can happen. Parents and their children are sometimes separated while escaping political conflicts ${ }^{39}$ or other events, such as natural disasters, in their home country. In other cases, job opportunities arise in a new society where a given parent or set of parents must immigrate to improve the livelihoods of themselves and their children. If they are accepted, these parents as new members of society have a strong interest in being able to continue to raise and nurture the development of their children that the new society should recognize by allowing the children to immigrate. ${ }^{40}$

Relatedly, there are many examples of people, usually women, in poor countries who have been abandoned by their spouses and left having to provide for their children alone. Sometimes these mothers have parents to call on to help with raising the children while they work. But often the amount of money that a single woman can make, for instance, in a small

\footnotetext{
${ }^{38}$ See Harry Brighouse and Adam Swift, Family Values: The Ethics of Parent-Child Relationships (Princeton: Princeton University Press, 2014), for one recent attempt to argue for this view.

${ }^{39}$ This has happened with many families fleeing the conflict in Syria. See Lizzie Dearden, 'Refugee Crisis: Lost Children Being Split from Parents Left "Vulnerable to Trafficking and Abuse", The Independent, September 10, 2015, http://www.independent. co.uk/news/world/europe/refugee-crisis-lost-children-being-split-from-parents-left-vulnerableto-trafficking-and-abuse-10494331.html, accessed March 26, 2017.

${ }^{40} \mathrm{I}$ am grateful to an anonymous reviewer for pressing me to clarify that my point is meant to apply once a parent becomes a member of the new society.
} 
rural town in Mexico is not enough to provide for their children on a sustainable basis even with the help of grandparents. ${ }^{41}$ These women do not want to leave their children behind - the choice is often excruciatingly difficult for them to make. It is out of love for their children and a broader acknowledgment of what they will need to flourish and develop into adults that mothers travel to richer countries to find work. For some years they send fund homes but long to have the chance to bring their children into the more prosperous society, and depend on the income they make in the new society to sustain their family. My claim is not that states are morally required to take in these parents, but instead that if these parents go through the process of becoming citizens, they should be allowed to bring their children into the new society. ${ }^{42}$ By doing so, the society will give appropriate consideration to their fundamental interest in participating in and maintaining their relationships with their children.

So far I have spoken to the closeness of the parent-child relationship from the parent's perspective and the importance of being able to bring one's children into the society that one is a member of. What of feasibility? My view is that by restricting the group of children of members that are obligatory unification admissions to non-adult unmarried children, a society can take in these children of members while meeting its other immigration-related responsibilities. There are two important considerations that favor this restriction. First, a society that was obligated to bring in all the children of its members would be required to accept long chains of immigrants who may want to enter, and such "chain migration" would constraint the number of the remaining immigrants from other groups that the society could bring in. A

\footnotetext{
${ }^{41}$ This case resembles the kind discussed by Leah Schmalzbauer at https://www.ncfr.org/ncfrreport/focus/immigration-migration/migration-separation-and-family-survival, accessed April 28, 2015. See also her The Last Best Place?: Gender, Family, and Migration in the New West (Stanford: Stanford University Press, 2014).

${ }^{42}$ This is compatible with there being other reasons to let the children immigrate even if the parent has violated some immigration laws or didn't acquire full citizenship.
} 
member of society with three adult children that themselves have two children each, for instance, would have the ability to put the society under an obligation to bring in nine people according to such a rule. One can see how quickly larger numbers per member could be generated if children of members were treated as an unrestricted group in the obligatory unification admissions category. This could easily jeopardize the society's ability to meet its other immigration-related responsibilities, both in terms of other obligatory unification admissions and any other groups, such as refugees, that must be admitted.

The second consideration in support of this restriction refers back to the importance of bringing in one's children. Adult and married children of members of society are typically past the point where their development as individuals should be significantly impacted by whether or not their parents live in the same society as they do. While parents often remain a strong source of guidance and advice throughout life, the interests of a parent in caring for and remaining closely involved in their child's life while he or she is developing into an adult becomes less significant as the child matures into adulthood. ${ }^{43}$ If they marry, they start a family of their own, which may or may not come to include children. The parent who is a member of society will likely still want to be a part of their lives, but the same caring and supporting relation does not obtain as the child becomes an adult and, if they do so, gets married. Caring relations in the other direction may obtain, of course, as I discussed earlier, where children seek to care for their parents. I don't deny that members of society may have interests in being cared for by their adult and married children. Given the fact that treating all adult and married children as obligatory

\footnotetext{
${ }^{43} \mathrm{I}$ 'm not certain of how to treat the issue of unification when a child has a severe developmental disorder that prevents them from acquiring the cognitive abilities to live as independent adults. I'm inclined to say that in these cases, they should be treated as obligatory unification admissions as it is often very important for both the parents and the child to continue to live together and not practically infeasible for most societies to allow for this limited additional flow of immigrants.
} 
unification admissions would be likely to render an immigration policy regime infeasible, appropriate consideration to these interests is compatible with not giving adult and married children this status. However, the interests of members in living with their adult and married children, both for their children's sake and their own, do provide some reason for the society to give extra weight to these non-members in comparison to the general pool of admissions.

\section{Spouses}

The last group of non-members that should be treated as obligatory unification admissions are spouses of members. I am also committed to the claim that societies must let in people who are about to be married to a member, but the issue of which non-members are obligatory unification admissions pertains to who must be not only let in but also allowed to become a member of society. In this section, I will argue for considerations in favor of obligatory unification admissions status for current spouses of members. ${ }^{44}$

The relationship between two spouses is typically of special importance in their lives. Because we have the ability to choose whether or not to develop a romantic relationship with another person, mature romantic relationships can provide value in our lives that is rarely found elsewhere. Finding that someone else whom we wish to commit to as our romantic and domestic partner reciprocates those desires and commitments with us can provide a unique kind of

\footnotetext{
${ }^{44}$ I do not have the space here to extend these points to the provision of marriage visas for fiancé(e)s of members. I will note here, however, that with a few restrictions, such as the requirement that the member and their fiancé(e) who has been brought in get married within a certain period of time (90 days for the "K-1 visa" in the United States), marriage visas can be part of a feasible immigration policy regime.
} 
affirmation, lifting our self-esteem and bolstering our confidence. ${ }^{45}$ When such relationships continue and flourish over time, the bonds between persons deepen and they are able to help one another through difficult experiences, while also sharing in their positive experiences. ${ }^{46}$

Marriage is not a perfect criterion for establishing that such a deep and mutually rewarding bond exists, but it provides a civic form of recognition for relationships between persons that are often especially valuable to them.

Why then is spousal unification ever necessary for a couple? As noted in the prior discussions of parents and children, people sometimes become separated during political conflicts or other events where they cannot escape to the same place. Additionally, one spouse's society may have very restrictive immigration rules that would prevent the other from getting in. There are also forms of discrimination that some romantic partners would face in many societies. In the case of marriages between homosexual or interracial couples, in particular, it may be the case that the couple would be subject to discrimination in the society where one of them lives. Even in places where they are legally able to marry, it may not be the case that they could safely live together. Lastly, sometimes one spouse must move to a new society to pursue professional or personal opportunities, or to take care of a family member. Here again, my claim is not that a society is, in every case, obligated to admit the first spouse arriving. As I have argued in the case of parent-child relationships, the point is that members have standing to demand that their

\footnotetext{
${ }^{45}$ This should not be taken to imply that unrequited love cannot be valuable. For an interesting defense of the value of unrequited love, see Sara Protasi, 'Loving People for Who They Are (Even When They Don't Love You Back)', European Journal of Philosophy, Vol. 21, No. 4 (2014), pp. 214-234.

${ }^{46}$ See Robert Nozick, 'Love's Bond', in The Examined Life (New York: Simon and Schuster, 1989), pp. 68-86. Nozick argues that mature romantic love involves the formation of a "we" by two people, a "new entity created by a new web of relationships between them which makes them no longer separate" (p. 70). I am not committed to Nozick's view, but part of what it attempts to capture is the shared experience of joy and sadness that mature romantic love brings.
} 
society allow them to bring in persons to whom they are particularly close if it would be feasible to do so. The society would violate their fundamental interests as persons in participating in and maintaining particularly close relationships with other persons by keeping their spouses out, which is unacceptable in the absence of a compelling reason to do so.

Of course, some spouses are denied the chance to unify and still manage to stay married. One such case was that of Nobel Prize winner, democratic activist, and first State Counsellor of Myanmar Aung San Suu Kyi and Michael Aris. ${ }^{47}$ During the ten-year period when she was placed under house arrest and leading up to Aris' death they only saw each other five times, with the last time being over three years before he passed away. I want to urge that despite their ability to remain married, Suu Kyi and Aris were wronged by being prevented from unifying. Their fundamental interests in participating in and maintaining their marital relationship were ignored by the Burmese government, among other interests of hers.

In some cases, spousal unification will also be important for the non-adult children of members, whom I've already argued should be treated as obligatory unification admissions. If a married couple consisting of a member and a non-member have children that are to be brought into the member's society, the children should not be denied the chance to live with both parents there. Most societies do not grant non-adult children who are members the ability to bring in parents as unification admissions, so the only unification request that could bring this person in would come from the parent who is a member in such societies. Even if one thinks that existing societies should do more to help children who are members unify with their parents who are nonmembers, the children will need representatives in such proposals to petition to bring in their parents. In practice, such measures will require coordination between representatives of the

${ }^{47}$ I am grateful to Steve Darwall for mentioning this case to me. 
children and the state, and will not be the quickest route for bringing in these parents. It will be greatly advantageous for these children, even if such policies are implemented, for their parents who are members to be able to bring in the other parent through marriage-based unification admissions.

In addition to the closeness of the relationship that spouses can have with one another and the importance of spousal unification, feasibility constraints do not militate against including spouses within the category of obligatory unification admissions. First, each member will only bring at most one spouse at a given time into a liberal democracy. These societies, which are the focus of our discussion, have converged on the judgment that polygamous relationships should not be lawful in their majority cultures. I cannot weigh in on the reasons for and against this judgment in this paper, but will simply note that polygamous marriages cannot be granted unification admissions status in these societies if they are not recognized between existing members. Because each member can bring in at most one spouse, spousal unification will not give rise to an unmanageable increase in admissions under ordinary circumstances.

Second, to minimize fraudulent claims, societies can request official marriage licenses and interview purported spouses regarding the nature of their relationship. Spouses typically also cohabitate, and this is something that the state can check on over time if there is reason to suspect that a fraudulent request for spousal unification has been made. As with other unification admissions requests, a petition to bring in a non-member spouse is made by a member of society. If reasons to suspect fraud emerge, for instance if many purported spouses are being petitioned over a few years by the same person, the member can be questioned and face substantial fines or even jail time if convicted of immigration-related marriage fraud. The ability to verify, with some degree of reliability, the fact that two people are genuinely married is part of 
what makes obligatory unification admissions status for spouses of members suitable for inclusion in a feasible immigration policy regime.

\section{Taking Stock}

In summary, the ability to live near and care for their parents, to raise their children to adulthood, and to share their lives with their spouses are important to the lives of members of society. Their lives may be significantly impacted for the worse by the inability to bring these persons into their society through immigration. Given that it would be feasible to do so, societies should treat their parents, children, and spouses, properly specified, as obligatory unification admissions. As argued above, giving obligatory unification admissions status to these nonmembers will secure the fundamental interests of members in participating in and maintaining particularly close relationships with them. One fundamental interest of persons is the interest in participating in and maintaining particularly close relationships with other persons. As a generalization, relationships with our parents, children, and spouses are particularly close relationships, and ones where fulfilling this interest will often require being able to live in the same society as these persons. These relationships are typically especially close ones and unification is important for participating in and maintaining them. Further, parent-child and spousal relationships, as I have specified them, do not give rise to long chains of migration and

can be verified with some degree of reliability. Granting obligatory unification admissions status to parents, non-adult unmarried children, and spouses of members is compatible with a society having a feasible immigration policy regime that is able to meet its other immigration-related responsibilities. 


\section{Contrasts with Other Relationships}

By contrast, the generalization that obligatory unification admissions status should be granted to siblings, aunts, uncles, nieces, nephews, cousins, or grandparents of members seems implausible. We may add adult children to this group, but I have already discussed why they should not be treated as obligatory unification admissions above. What is different about these relationships? As I've mentioned, in particular cases the relationships between members and these non-members may be especially close and important for them, to the point where the fact that they cannot unify will significantly impact their lives. I concede that Ferracioli is entirely right about this. Yet these cases are far more rare than cases where parent-child and spousal relationships, properly specified, are of this level of importance for the persons in them. Because societies must implement general policies regarding non-members who they will take in and do so in a way that is compatible with meeting their other immigration-related responsibilities, they must grant obligatory unification admissions status in a way that captures the types of relationships for which unification is typically most pressing. This is an important difference between the parent-child and spousal relationships discussed above and relationships with these other family members. The former typically rise to the level of importance where the fundamental interests of members can be affected by unification policies, where this isn't a plausible generalization about the latter. ${ }^{48}$

\footnotetext{
${ }^{48}$ One way in which these other family relationships may be especially close is if some of these family members played the role of a parent in our lives. As I argued above, the reasoning in favor of granting obligatory unification admissions status to parents of members extends to other persons who played this parental role. This consideration doesn't give us a reason, then, to treat relationships with siblings, aunts, uncles, nieces, nephews, cousins, or grandparents as such on a par with parent-child and spousal relationships.
} 
As I've noted, some members of society may have fundamental interests in participating in and maintaining close relationships with these other family members, where these interests are set back by the inability to bring them in as new members. My view accommodates this fact because it holds that when it is the case that granting unification admissions status to a category of immigrants would be infeasible for a society, appropriate consideration to these interests does not require the society to do so. As I've argued, parent-child and spousal relationships, properly specified, require unification for the fundamental interests of members to be fulfilled far more often than do these other family relationships, which are typically less close and do not require unification to be maintained. These parent-child and spousal relationships should therefore be the relationships that are granted obligatory unification admissions status when this status cannot feasibly be given to all relationships.

A straightforward extension of these points demonstrates that Ferracioli is also mistaken in concluding that we cannot justify leaving friends and creative partners out of the obligatory unification admissions category. Once again, I concede that, on a case-by-case basis, it may be just as important for certain people to be able to bring in their friends or creative partners as it is for others to bring in their parents, children, or spouses. It is far more rare, however, that friendships or creative partnerships involve fundamental interests of members that cannot be fulfilled unless certain persons are allowed to immigrate. Friendships typically can be carried on abroad with sporadic visits, and many creative partnerships can be sustained digitally, as coauthors in philosophy know well. Given the requirements of feasibility, appropriate consideration to the fundamental interests of members who wish to bring in these other persons does not require granting them obligatory unification admissions status. 
Additionally, while my argument doesn't rest on this point, there are important differences between the means that can be used to verify parent-child and spousal relationships as compared with friendships, and at least many creative partnerships. With respect to the creative partnerships that Ferracioli has in mind, I will assume that these do not already fall under the category of persons that can be sponsored for work visas, ${ }^{49}$ since this would largely obviate the need to bring such persons in through the unification stream. ${ }^{50}$ The same contrast with respect to means of verification can also be made between other family members and the friends and creative partners of members of society, with the qualification just mentioned. ${ }^{51}$ In the case of family members, DNA tests ${ }^{52}$ and family legal records can be and are in fact used to determine the veracity of claims when suspicions arise. With spouses, evidence of shared financial holdings, such as joint bank accounts, and cohabitation are often used as evidence of the relationship. Of course, sham marriages are sometimes entered into for purposes of

${ }^{49}$ A further point to note here is that some of the creative partnerships that Ferracioli has in mind, such as that of bandmates "Maddy and Oscar" from Madagascar who have been "working together for 20 years" ('Family Migration Schemes and Liberal Neutrality: A Dilemma', p. 570), could potentially make use of visas for musicians and other artists that many countries provide. Of course, receiving these visas can involve meeting somewhat demanding criteria. In the United States, for instance, members of musical groups that work in a traditional or unique art form, or who are internationally renowned, can apply for a "P visa," where "P" refers to 8 U.S.C. $\S 1101(\mathrm{a})(15)(\mathrm{P})$, Section 101 of the Immigration and Nationality Act of 1965.

${ }^{50}$ Additionally, when two people have established an ongoing working relationship of the kind that could make a work visa sponsorship possible, there is generally substantial evidence of the relationship that can be provided and verified.

${ }^{51}$ I here drop the qualification that these creative partners do not qualify for work visas for ease of exposition.

${ }^{52}$ Countries that use DNA testing to verify family relationships in immigration include Australia, Canada, Denmark, Finland, the Netherlands, New Zealand, Norway, Sweden, the United Kingdom, and the United States. For a helpful discussion of this practice, see Jackie Taitz, Jacqueline E.M. Weekers, and Davide T. Mosca, 'The Last Resort: Exploring the Use of DNA Testing for Family Reunification', Health and Human Rights, Vol. 6, No. 1 (2002), pp. 20-32. 
immigration. ${ }^{53}$ But in spousal and family admissions, these hard forms of evidence can be provided for verification purposes. Of course, as with spouses and family members, immigration officials could use interviews and request various forms of evidence, such as past correspondence and photos, ${ }^{54}$ to try to ascertain whether people are close friends. But no similar forms of hard evidence are generally available for verifying such friendships. For creative partnerships that fall short of the kinds of working relationships that can make use of work visas, the same is true. While I have argued that states do not have to grant obligatory unification admissions status to family members other than parents, non-adult unmarried children, and spouses, these other family relationships are not difficult or particularly costly to verify. I cannot fully make the case in this paper, but this suggests that societies may be justified in treating these other family members as optional unification admissions, preferring them over general

\footnotetext{
${ }^{53}$ State immigration agencies sometimes exaggerate the prevalence of marriage-based immigration fraud, sometimes to great effect. For instance, the U.S. Immigration and Naturalization Service (INS) claimed that 30 percent of marriage-based immigration was fraudulent in the congressional hearings on the Immigration and Marriage Fraud Amendments of 1986 (IMFA). This claim had a large effect on support for the IMFA in Congress. Only limited hearing was given to testimony that questioned the claim, such as the statement given by Jules E. Coven, then President of the American Immigration Lawyers Association. A later study cast doubt on the accuracy of the statistical claim made, finding that the denial rate for marriagebased immigration was only 4.6 percent (see 'INS Reveals Basis for Fraud Claims', Interpreter Releases, No. 65, (1988), pp. 26-7). While it's possible that there was a gap between the rate at which marriage-based fraud was detected and the rate at which fraudulent claims were denied in the U.S., it is very unlikely that a difference of this magnitude could be explained in this way. See J.A. Tucker, "Assimilation to the United States: A Study of the Adjustment of Status and the Immigration Marriage Fraud Statutes," Yale Law \& Policy Review, Vol. 7, No. 1 (1989), pp. 20 110. For important criticisms of the effects of provisions in the IMFA and subsequent INS regulations that apply to women seeking to avoid deportation while separating from their citizen partners, see Uma Narayan, "Male-Order" Brides: Immigrant Women, Domestic Violence and Immigration Law', Hypatia, Vol. 10, No. 1, (Winter 1995), pp. 104-119.

${ }^{54}$ For a helpful overview of the kinds of questions that couples may be asked in their interviews with United States Citizenship and Immigration Services (USCIS) officials, see Ilona Bray, Fiancé and Marriage Visas: A Couple's Guide to U.S. Immigration, $9^{\text {th }}$ edition (Berkeley: Nolo, 2016). In addition to answering any number of factual questions about their relationship and providing past correspondence and photos, couples are often asked to show that they have matching house keys in their possession.
} 
admissions, while not giving any official unification status to friends or creative partners. ${ }^{55}$ To monitor and verify friendships and creative partnerships with the same level of certainty that DNA tests, family legal records, joint financial holdings, and cohabitation provide would probably require immigration services to track people's activities closely over time, which would be very costly. While societies can reasonably determine whether people really stand in family or spousal relationships with their members using relatively inexpensive and easily applied methods, the same cannot plausibly be said for friendships and creative partnerships.

\section{Conclusion}

The traditional state sovereignty view on immigration has been thought to involve a commitment to a society's responsibility to give preferential treatment to relatives and spouses seeking admission. Ferracioli presents liberal theorists who agree that these non-members should be given preferential treatment with a dilemma. According to Ferracioli, the requirement of liberal neutrality implies that societies should treat all or nearly all relationships between members and non-members on a par. Hence, liberals are faced with the dilemma of having either to concede that a much wider array of relationships must be recognized by an immigration policy regime or give up the view that members have legitimate demands to bring in relatives and spouses. I have shown that liberals can deny the first horn of this dilemma without relying on any substantive commitments of the traditional state sovereignty view, in particular the wide

\footnotetext{
${ }^{55}$ I am grateful to an anonymous reviewer for pushing me to clarify the fact that by granting optional unification admissions status to the additional family members mentioned here, refugee admissions will not be decreased, because refugees are an obligatory admissions category. As I have defined them, optional unification admissions can be refused if there are too many immigrants from another category seeking to enter, such as refugees.
} 
latitude that it ascribes to states in matters of immigration. By contrast with alternatives that would rely on claims about intrinsic differences between relationships in terms of their moral significance or importance to justify treating them differently in immigration, my view retains a commitment to liberal neutrality. The justification that I've given for distinguishing between different categories of unification admissions does not appeal to a particular conception of the good or comprehensive doctrine. Rather, it appeals to the need to implement a feasible immigration policy regime while giving appropriate consideration to the fundamental interests of members in unifying with certain non-members that they are in particularly close relationships with. My view does not claim that the non-members who should be granted obligatory unification admissions status are parties to intrinsically better or more important relationships with members than others. It instead relies on the generalization that parent-child and spousal relationships, properly specified, are the ones that tend to require unification for the fundamental interests of members to be fulfilled. Given that not all non-members in morally significant relationships with members can be granted obligatory unification admissions status, parents, non-adult unmarried children, and spouses of members are the ones to whom this status should be granted. ${ }^{56}$

\footnotetext{
${ }^{56}$ I would like to thank Christian Barry, Bob Goodin, Peter McDonald, Iddo Porat, James Raymer, and Peter Singer for comments and discussion on the points raised in this paper. For written comments, I am especially grateful to Steve Darwall, Luara Ferracioli, Serene Khader, Josh Knobe, Tally Kritzman-Amir, RJ Leland, Emily McTernan, Daniel Putnam, Nic Southwood, and two anonymous reviewers for the journal.
} 